\title{
Incidence of end stage renal disease on renal replacement therapy in Nepal
}

\author{
Hada R', Khakurel S1, Agrawal RK ${ }^{1}$, Kafle RK ${ }^{2}$, Bajracharya SB ${ }^{3}$, Raut KB ${ }^{4}$
}

${ }^{1}$ National Academy of Medical Sciences, Bir Hospital, ${ }^{2}$ National Kidney center, ${ }^{3}$ Shree Birendra Hospital, Chhauni, ${ }^{4}$ Tribhuban University Teaching Hospital

\begin{abstract}
Background: End stage renal disease patients are treated with dialysis in Nepal. But there is no renal registry to indicate the burden of disease in the country.

Objectives:The objective of this study is to find out the incidence of ESRD on renal replacement therapy and their out come.

Materials and methods: It is a retrospective analysis (audit) of all ESRD patients who had received dialysis inside Nepal and had under gone transplantation from 1990 to 1999. The haemodialysis (HD) registry, HD patients file, intermittent peritoneal dialysis (IPD) registry of Bir Hospital, Shree Birendra Hospital, Tribhuwan University Teaching hospital and National Kidney Center were reviewed. Acute renal failure and acute on chronic renal failure were excluded and the demographic profile, dialysis session, dialysis duration and outcome of all ESRD patients were computed. One patient was counted only once in spite of attending more than one center for dialysis. SPSS package was used for analysis.

Results: Total number of 1393 ESRD patients received renal replacement therapy (RRT) in the decade. Mean age of patients were $46.7 \pm 16.7$ with $70 \%$ of ESRD were between $20-60$ years age with male: female ratio of 1.8:1. Initial mode of RRT was IPD in $58.2 \%$, HD in $41.7 \%$ and pre-emptive transplantation in $0.1 \%$ patients. Records of 189 patients could not be found and out of remaining 1208 patients, $85.8 \%$ received dialysis for $<3$ months, $6 \%$ received dialysis for more than a year and 9.5\% had undergone kidney transplantation. The incidence of ESRD had increased gradually with 3.4 per million populations (pmp) in 1990 to $11.89 \mathrm{pmp}$ in 1999 with an average annual incidence of 6 pmp and only $0.31 \%$ of expected ESRD patients received RRT.

Conclusion: The incidence of ESRD is increasing but majority discontinue or die within 3 months. Dialysis centers needs to be expanded to different parts of country and prospective studies have to be carried out to find out of cause of ESRD and to institute preventive measures.
\end{abstract}

Key words: End stage renal disease, Renal replacement therapy, Haemodialysis, Intermittent peritoneal dialysis, Incidence of end stage renal disease, Nepal.

$\mathrm{E}_{\mathrm{r}}^{\mathrm{n}}$ nd stage renal disease (ESRD) is a common and rapidly increasing public health problem all over the world, both in developed and developing countries, consuming a bulk of economy in treating these patients ${ }^{1}$. The National and international registries on ESRD and renal replacement therapy (RRT) in developed countries have highlighted the incidence, prevalence, etiology, prognostic factors, survival and mortality of ESRD patients $^{2,3}$. But in most of the developing countries such registries and government health policy to support these patients is lacking with the variation of reported annual incidence of ESRD 34 to 240 per million population $(\mathrm{pmp})^{4}$. Due to lack of exact figure, the incidence of ESRD is estimated to be 100 per million populations (pmp) in South Asian countries Pakistan, India and Bangladesh ${ }^{5,6,7}$.
Nepal, another South Asian country, had started dialysis service with initiation of intermittent peritoneal dialysis (IPD) in 1972 and establishment of haemodialysis (HD) unit in 1987 in Bir hospital ${ }^{8}$.

To cope up with increasing number of ESRD patients, HD was started in Shree Birendra hospital in December 1995, Tribhuban University Teaching Hospital (TUTH) in April 1996 and National Kidney Center (NKC) in April 1997 and other private hospitals after 2000. There were total $15 \mathrm{HD}$ machines and 9 Nephrologists in the country, all in capital by the end of 1999 and IPD

\footnotetext{
Correspondence

Dr. Rajani Hada

Associate Professor,

National Academy of Medical Sciences,

Bir Hospital, Kathmandu, Nepal

E-mail: rajani.hada@hotmail.com
} 
was practiced only in Bir hospital during the period. Continuous ambulatory peritoneal dialysis (CAPD) is performed quite infrequently and kidney transplantation has just started this year.

ESRD and RRT registry is not yet started and no data compiled to indicate the incidence of ESRD and / or RRT in Nepal. So, this retrospective study was carried out to highlight the extent of ESRD on RRT and their outcome.

\section{Materials and methods}

It is a retrospective analysis of all ESRD patients who had received one or other form of renal replacement therapy (RRT) in Nepal from January 1990 to December 1999. The haemodialysis enrollment registers and haemodialysis patient files in Bir hospital, Shree Birendra hospital, TUTH and NKC and IPD register in Bir hospital were reviewed. Acute renal failure and acute on chronic renal failure was excluded and only the patients with ESRD were included. Patients name, age, sex, address were enlisted alphabetically to avoid inclusion of same patient more than once. From IPD register, total session of IPD and outcome were recorded and from haemodialysis patients file total session, total duration of dialysis and outcome were recorded to find out the survival of these patients. As there was no etiology recorded in these dialysis registers, the cause of ESRD could not be analysed. The first dialysis enrollment date for RRT was included as the date of registration. Same patient attending a different center is counted only once. Any patient with confusion is deleted from the study. From the records of transplantation patients in outpatient department of these centers, the transplantation patients were included as ESRD patients if they had undergone pre-emptive transplantation. Results of this study were analysed by using SPSS software.

Results

Thirteen hundred and ninety-three ESRD patients received RRT in 10 years (1990-1999) in Nepal. 1391 patients received dialysis and 2 patients had undergone pre-emptive transplantation in India. Out of 1391 patients, 46 patients received dialysis in more than one centre. Mean age of patients was $46.7 \pm 16.7$ years with age ranging from 8 to 89 years. $905(65 \%)$ patients were male and $488(35 \%)$ patients were female with male to female ratio of $1.8: 1$.

On grouping of the subjects according to age distribution $86(6.2 \%)$ patients were up to 20 years, $439(31.5 \%)$ patients were of $>20$ to 40 years age, 549 (39.4\%) patients were of $>40$ to 60 years age and 319 (22.9\%) patients were of $>60$ years showing $70 \%$ of ESRD in productive age group (20-60 years).

\section{Incidence of ESRD on RRT}

Annual incidence of ESRD patients during the study period is shown in Table 1 and Fig. 1.

There is gradual increase in number of patients of ESRD each year with 61 patients in 1990 to 270 patients in 1999 and an increasing trend has affected all age groups and both sex.

Calculation of total incidence of ESRD on RRT per million populations (pmp) of Nepal has shown rise of incidence from $3.4 \mathrm{pmp}$ in 1991 to $11.89 \mathrm{pmp}$ in 1999 with an average of $6 \mathrm{pmp}$ in the decade. On calculating the percentage of RRT given in Nepal with estimated incidence of ESRD 100 pmp per year as par with South Asian countries $5,6,7$, only $0.31 \%$ ESRD had received RRT in that decade.

\section{Mode of RRT and survival of patients}

Out of 1393 ESRD patients, 2 had pre-emptive transplantation, $810(58.2 \%)$ had IPD [160 (11.5\%) had IPD followed by HD] and 581 (41.7\%) had only HD. Among total number of $741(53.2 \%)$ patients on HD the records of $189(13.6 \%)$ ESRD patients could not be found.

So on further analysis of total 1204 ESRD patients on RRT, 115 (9.5\%) patients had undergone transplantation (2 - pre-emptive, 3 after IPD and 110 after HD) and 6 $(0.45 \%)$ patients on HD had switched over to CAPD. Out of remaining 1083 (89.95\%) ESRD patients, 647 $(59.7 \%)$ received only IPD and $436(40.3 \%)$ received HD [339 (31.3\%) had only HD and 97 (9\%) had IPD followed by HD].

All patients on IPD received dialysis for $<3$ month though $511(36.6 \%)$ received 1 session, 98 received 2 sessions, 24 received 3 sessions, 8 received 4 sessions, 3 received 5 sessions, 3 received 6 sessions.

On analysis of patients on HD, $282(26 \%)$ had dialysis for $<3$ months, $95(8.7 \%)$ had dialysis for $<1$ year and $59(5.4 \%)$ had dialysis for $>1$ year.

So, total number of 929 (85.8\%) ESRD patients had dialysis for $<3$ months and only $59(5.4 \%)$ patients had maintenance dialysis for more than 1 year. But on including 15 patients in HD for $>$ than 1 year prior to transplantation and CAPD, total 74 (6.1\%) patients had survived for $>1$ year in HD.

Survival of these patients is shown in Table 2. Among 4 patients with survival for $>$ than 5 years 1 deceased on MHD, 1 deceased after switching to CAPD and 2 are still surviving ( 1 has completed 10 years \& another has completed 9 years). 
Table 1: Annual incidence of ESRD with renal replacement therapy in Nepal

\begin{tabular}{|c|c|c|c|c|c|}
\hline Years & $\begin{array}{l}\text { Total } \\
\text { number of } \\
\text { ESRD on } \\
\text { RRT }\end{array}$ & $\begin{array}{l}\text { Total population of } \\
\text { Nepal }^{\text {b }} \\
\text { (in million) }\end{array}$ & $\begin{array}{l}\text { Total number of } \\
\text { ESRD on RRT per } \\
\text { million population } \\
\text { (pmp) }\end{array}$ & $\begin{array}{l}\text { Estimated incidence of } \\
\text { ESRD with } 100 \text { pmp per } \\
\text { year as par with South } \\
\text { Asian countries }\end{array}$ & $\begin{array}{c}\text { Proportion of } \\
\text { patient receiving } \\
\text { RRT in \% }\end{array}$ \\
\hline 1990 & 61 & $17.9^{\mathrm{a}}$ & 3.4 & 1790 & 0.18 \\
\hline 1991 & 68 & 18.4 & 3.6 & 1840 & 0.19 \\
\hline 1992 & 97 & 19.0 & 5.1 & 1900 & 0.26 \\
\hline 1993 & 78 & 19.5 & 4.0 & 1950 & 0.20 \\
\hline 1994 & 125 & 20.0 & 6.25 & 2000 & 0.31 \\
\hline 1995 & 134 & 20.5 & 6.53 & 2050 & 0.31 \\
\hline 1996 & 159 & 21.2 & 7.5 & 2120 & 0.35 \\
\hline 1997 & 189 & 21.6 & 8.75 & 2160 & 0.40 \\
\hline 1998 & 212 & 22.1 & 9.59 & 2210 & 0.43 \\
\hline \multirow[t]{2}{*}{1999} & 270 & 22.7 & 11.89 & 2270 & 0.52 \\
\hline & $1393(100 \%)$ & & Average -6.0 & & Average $-0.31 \%$ \\
\hline
\end{tabular}

${ }^{a}$ Estimated population on the basis of population growth from 1991 to 1992 using exponential growth rate model $\left(\mathrm{P}_{1991}=\mathrm{P}_{1990} \mathrm{X} \mathrm{e}^{\mathrm{rt}}\right)$.

${ }^{\mathrm{b}}$ Projected population (Median variant) by sex and single calendar year, Population projection of Nepal, $1991-2011$, Central Bureau of Statistics.

${ }^{c}($ ESRD on RRT pmp $\div$ Estimated incidence of ESRD with 100 pmp per year) x 100

Table 2: Survival in years of ESRD patients on Dialysis

\begin{tabular}{|l|c|c|c|}
\hline & Only on dialysis & $\begin{array}{c}\text { Dialysis prior to } \\
\text { transplantation and CAPD }\end{array}$ & Total \\
\hline$>1-2$ years & 34 & 9 & 43 \\
\hline$>2-3$ years & 13 & 2 & 15 \\
\hline$>3-4$ years & 5 & 2 & 7 \\
\hline$>4-5$ years & 4 & 1 & 5 \\
\hline$>5$ years & 3 & 1 & 4 \\
\hline Total & $\mathbf{5 9}$ & $\mathbf{1 5}$ & $\mathbf{7 4}$ \\
\hline
\end{tabular}

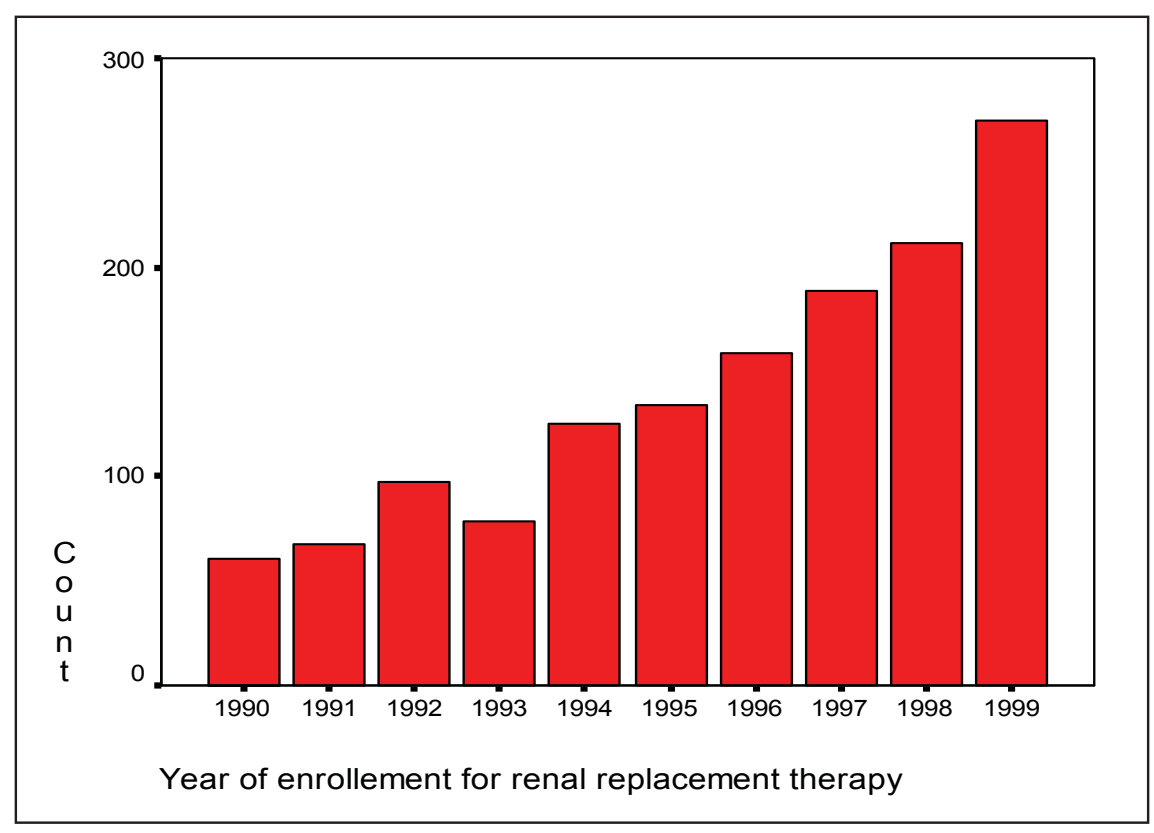

Fig 1: Annual incidence of ESRD patients 


\section{Discussion}

Due to lack of health education, centralised dialysis facilities, under diagnosis \& inadequate referral from peripheral hospitals and low socioeconomic conditions, the result of this study indicates the tip of ice berg of ESRD in this country and majority of patients must have died without diagnosis and reaching central hospitals.

Mean age of ESRD patients were $46.7 \pm 16.7$ years, older than reported in developing countries - Bangladesh, India and Pakistan (38-42 years) $)^{7,9,10}$, much younger than developed countries $(>60 \text { years })^{11}$ and $70 \%$ patients were of productive age group from 20- 60 years.

Present study has shown predominance of male $(65 \%)$ over female (35\%) similar to other studies in India $(67.8 \% \text { male and } 32.2 \% \text { female })^{12}$, Saudi Arabia $(64.5 \%$ male and $35.5 \%$ female $)^{13}$ and Japan (54.4\% male and $45.6 \%$ female $)^{14}$.

With increasing population, the incidence of ESRD patients is increasing dramatically all over the world. Due to lack of registries, the estimated annual incidence of ESRD in South Asian countries ${ }^{5,6,7}$ is 100 pmp though the number of patients enrolled for dialysis is only 3-5 pmp in India ${ }^{15}$. Present study has shown gradual increase of incidence of ESRD patients with $3.6 \mathrm{pmp}$ in 1990 to $11.8 \mathrm{pmp}$ in 1999 with an average annual incidence of ESRD on RRT of 6 pmp. RRT was given to only $0.31 \%$ of estimated ESRD patients (Table- 1 ) showing inadequate referral, under diagnosis and need of expansion of dialysis facility to peripheral hospitals.

Due to unavailability of adequate number of HD machines and financial constraint of patients, IPD using rigid stylet-based catheter was performed as a temporary means of dialysis of ESRD patients in many developing countries though survival of ESRD patient (6 months -2.5 years) with IPD was reported in Bangladesh in $1984^{16}$. With increasing dialysis centers in government and private hospital, IPD is now restricted to remote areas of India $^{17}$. IPD as the initial mode of dialysis in $58.2 \%$ and HD in $41.7 \%$ ESRD patients in the present study indicate the inadequate number of HD machines.

Due to poor economic status $60 \%$ of HD patients in India discontinue dialysis within 3 months, $17 \%$ undergo kidney transplantation, $13 \%$ die within 1 year and $4 \%$ remain on MHD for more than 1 year $^{6}$. Moreover due to high cost of RRT, $30 \%$ of patients on dialysis in Bangladesh abandon treatment within 3 months after the start of dialysis and die and 10\% undergo transplantation ${ }^{7}$. In the present study, $85.8 \%$ patients discontinued dialysis and died within 3 months, $8.7 \%$ died within 1 year, $6 \%$ survived for more than 1 year on dialysis and $9.5 \%$ had undergone transplantation indicating the poor outcome of ESRD patients in Nepal till this decade.

Conclusion

The incidence of ESRD patients are increasing in all age group and sex.

Majority of patients discontinue dialysis and die within 3 months. Hence, Dialysis needs to be given more attention. Dialysis centers need to be expanded to different parts of country. Prospective studies have to be carried out to find out of cause of ESRD and institute preventive measures.

\section{Acknowledgement}

Dr Dibya Singh, Associate Professor, Nephrology Unit, TUTH, Dr Arun Sharma, Consultant Nephrologists, Shree Birendra Hospital and Dr Dineshwori Shrestha, Bir hospital for helping in data collection.

\section{References}

1. Arikan H, Tuglular S. The growing global burden of end stage renal disease (ESRD). Marmara Medical College Journal. 2005;18 (3): 143-50.

2. Stengel B, Billon S, Dijk PCW, Jager KJ, Dekker FW, Slimpson K, et al. Trends in the incidence of renal replacement therapy for end-stage renal disease in Europe, 1990-1999. Nephrol Dial Transplant. 2003;18:1824-33.

3. Wakai K, Nakai S, Kikuchi K, Iseki K, Miwa N, Masakane I, et al. Trends in incidence of endstage renal disease in Japan, 1983-2000: ageadjusted and age specific rates by gender and cause. Nephrol Dial Transplant. 2004;19:204452.

4. Chugh KS, Jha V and Chugh S. Economics of dialysis and renal transplantation in the developing world. Transplant Proc. 1999;31:3275-7.

5. Naqvi SAJ. Nephrology services in Pakistan. Nephrol Dial Transpl. 2000;15: 769-71.

6. Kher V. End-stage renal disease in developing countries. Kidney Int. 2002;62: 350-62.

7. Rashid HU. Health delivery system for renal disease care in Bangladesh. Saudi J kidney Dis Transpl. 2004;15:185-9.

8. Hada R. Kidney transplantation in Nepal. PMJN. 2003;4:51-4.

9. Sakhuja V, Sud K. End-stage renal disease in India and Pakistan: burden of disease and management issues. Kidney Int suppl. 2003;83:S115-8. 
10. Rao M, Juneja R. Shirly $R$ and Jacob $\mathrm{S}$. Haemodialysis for end stage renal disease in Southern India - a perspective from a tertiary referral care center. Nephrol Dial transplant. 1998;13:2494-500.

11. United States Renal Data System. 1999 Annual Data Report. Am J Kidney Dis. 1999; 34 (2 Suppl 1):S1-176.

12. Mittal s, Kher V, Gulati s, Agrawal LK, Arora P. Chronic renal failure in India. Ren Fail. 1997;19(6):763-70.

13. AI Wakeel JS, Mitwalli AH, AI Mohaya S, AbuAisha H, Tarif N, Malik GH, et al. Morbidity and mortality in ESRD patients on dialysis. Saudi J kidney Dis Transplant. 2002;13:473-7.
14. Iseki K, Iseki C, lkemiya Y, Fukiyama K. Risk of developing end stage renal disease in a cohort of mass screening. Kidney Int. 1996;49(3):800-5.

15. Jha V and Chugh KS. Dialysis in developing countries: Priorities and obstacles. Nephrology. 1996; 2: 65-72.

16. Rashid HU, Kabir $\mathrm{Z}$ and Bari R. Intermittent peritoneal dialysis $-21 / 2$ years experience in IPGMR. Bangladesh Med Res Counc Bull. 1984;10:59-64.

17. Jha V. and Chugh KS. The practice of dialysis in developing countries. Haemodialysis International. 2003;7:239-49. 